\title{
Size dimorphism and sexual segregation in pheasants: tests of three competing hypotheses
}

\author{
Mark A Whiteside ${ }^{\text {Corresp., }}{ }^{1,2}{ }^{\text {， Jayden } O}$ van Horik ${ }^{1}$ ， Ellis JG Langley ${ }^{1}$ ， Christine E Beardsworth ${ }^{1}$, Joah R Madden \\ ${ }^{1}$ Centre for Research in Animal Behaviour, University of Exeter, Exeter, Devon, United Kingdom \\ ${ }^{2}$ Game and Wildlife Conservation Trust, Fordingbridge, Hampshire, United Kingdom \\ Corresponding Author: Mark A Whiteside \\ Email address: M.Whiteside@exeter.ac.uk
}

Fine scale sexual segregation outside of the mating season is common in sexually dimorphic and polygamous species, particularly in ungulates. A number of hypotheses predict sexual segregation but these are often contradictory with no agreement as to a common cause, perhaps because they are species specific. We explicitly tested three of these hypotheses which are commonly linked by a dependence on sexual dimorphism for animals which exhibit fine-scale sexual segregation; the Predation Risk Hypothesis, the Forage Selection Hypothesis, and the Activity Budget Hypothesis, in a single system the pheasant, Phasianus colchicus; a large, sedentary bird that is predominantly terrestrial and therefore analogous to ungulates rather than many avian species which sexually segregate. Over four years we reared 2400 individually tagged pheasants from one day old and after a period of 8-10 weeks we released them into the wild. We then followed the birds for 7 months, during the period that they sexually segregate, determined their fate and collected behavioural and morphological measures pertinent to the hypotheses. Pheasants are sexually dimorphic during the entire period that they sexually segregate in the wild; males are larger than females in both body size and gut measurements. However, this did not influence predation risk and predation rates (as predicted by the Predation Risk Hypothesis), diet choice (as predicted by the Forage Selection Hypothesis), or the amount of time spent foraging, resting or walking (as predicted by the Activity Budget Hypothesis). We conclude that adult sexual size dimorphism is not responsible for sexual segregation in the pheasant in the wild. Instead, we consider that segregation may be mediated by other, perhaps social, factors. We highlight the importance of studies on a wide range of taxa to help further the knowledge of sexual segregation. 
1 Size dimorphism and sexual segregation in pheasants: tests of three competing hypotheses

2

3 Mark A. Whiteside ${ }^{1,2 *}$, Jayden O. van Horik ${ }^{1}$, Ellis J G. Langley ${ }^{1}$, Christine E. Beardsworth ${ }^{1}$ and

4 Joah R. Madden ${ }^{1}$

5

6 1. Centre for Research in Animal Behaviour, Psychology, University of Exeter, Exeter, EX4 4QG, UK

2. Game and Wildlife Conservation Trust, Burgate Manor, Fordingbridge, Hampshire, SP6 $1 \mathrm{EF}$

*Author for correspondence: email M.Whiteside@exeter.ac.uk

\section{Acknowledgements}

We thank RA Wills and Rothamsted Research for access to their land. The gamekeepers, Steve Ridge and Jeremy Stickland, provided information and technical assistance. Aiden Hulatt, Seb Bekker, Kenzie Bess, Jack Buckingham, Louise Dean, Pip Laker, Rachel Peden, Chris Peel, Sara Raj Pant, Louise Saul and Alicia Wiltshire assisted with collecting the observational data, analysing photos from camera traps, and conducting experiments. We thank Dr Rufus Sage for his advice and constructive criticism of the manuscript. 
24 Abstract

25

Fine scale sexual segregation outside of the mating season is common in sexually dimorphic and polygamous species, particularly in ungulates. A number of hypotheses predict sexual segregation but these are often contradictory with no agreement as to a common cause, perhaps because they are species specific.

We explicitly tested three of these hypotheses which are commonly linked by a dependence on sexual dimorphism for animals which exhibit fine-scale sexual segregation; the Predation Risk Hypothesis, the Forage Selection Hypothesis, and the Activity Budget Hypothesis, in a single system the pheasant, Phasianus colchicus; a large, sedentary bird that is predominantly terrestrial and therefore analogous to ungulates rather than many avian species which sexually segregate.

Over four years we reared 2400 individually tagged pheasants from one day old and after a period of 8-10 weeks we released them into the wild. We then followed the birds for 7 months, during the period that they sexually segregate, determined their fate and collected behavioural and morphological measures pertinent to the hypotheses.

Pheasants are sexually dimorphic during the entire period that they sexually segregate in the wild; males are larger than females in both body size and gut measurements. However, this did not influence predation risk and predation rates (as predicted by the Predation Risk Hypothesis), diet choice (as predicted by the Forage Selection Hypothesis), or the amount of time spent foraging, resting or walking (as predicted by the Activity Budget Hypothesis).

We conclude that adult sexual size dimorphism is not responsible for sexual segregation in the pheasant in the wild. Instead, we consider that segregation may be mediated by other, perhaps social, factors. We highlight the importance of studies on a wide range of taxa to help further the knowledge of sexual segregation. 


\section{Introduction}

Sexual segregation, in which females and males are separated in time and/or space outside of the mating season, is common in a variety of birds, mammals, fish and reptiles (Bleich et al. 1997; Ruckstuhl \& Neuhaus 2005; Ruckstuhl \& Neuhaus 2000). Fine scale sexual segregation, in which segregation occurs within a small area, is particularly prevalent in species with strong sexual dimorphism (Ruckstuhl \& Neuhaus 2002) and those with polygynous mating systems (Clutton-Brock 1989). However, there is little consensus about the underlying factors driving sexual segregation (Alves et al. 2013; Bonenfant et al. 2007).

Sexual body-size dimorphism can result in differential: 1) metabolic rates and absolute intake requirements (Demment \& Van Soest 1985); 2) ability to digest and absorb nutrients (Demment \& Van Soest 1985); 3) physical characteristics (e.g. molar size, Lüps \& Roper 1988); and 4) parasite infection rates and immuno-competence (Stoehr \& Kokko 2006; Zuk \& McKean 1996) between the sexes. These differences underlie the four main, but non-exclusive, hypotheses proposed to explain why sexual segregation occurs in polygynous populations that are commonly linked by a dependence on sexual (size) dimorphism (Bon \& Campan 1996; Bowyer 2004; Ruckstuhl \& Neuhaus 2005). The first, the Predation Risk Hypothesis (PRH), or Reproductive Strategy Hypothesis, postulates that sexual segregation results from each sex investing differentially in strategies to maximise their own reproductive success (Main \& Coblentz 1996). Females, perhaps accompanied by dependent and vulnerable young, avoid higher predation risks and forage in places or at times that offer lower nutrient intake (Corti \& Shackleton 2002; Main \& Coblentz 1996). In contrast, males may opt to maximize their competitive advantage by investing in growth and therefore exploit nutrient rich habitats despite the increased risk of predation (Clutton-Brock et al. 1982; Prins 1989). The second, the Forage Selection Hypothesis (FSH), or Sexual Dimorphism Body-size Hypothesis (Main 1996), predicts that allometric differences in body size, bite size, energy requirements and/or fibre digestion between the sexes can lead to differences in diet selection and habitat choice (Barboza \& Bowyer 2000; Demment 1982; Main \& Coblentz 1996). Individuals with a smaller gut system are less able to digest lower quality food items and are predicted to feed on higher quality diets than larger conspecifics (Barboza \& Bowyer 2001; Demment \& Van Soest 1985). The third, the Activity Budget Hypothesis states that body size dimorphism promotes differences in activity 
84 budgets and synchrony of these behaviours results in aggregation of the sexes (Conradt 1998;

85 Ruckstuhl \& Neuhaus 2002; Ruckstuhl \& Neuhaus 2000). Here, energetic requirements and

86

87

88

89

90

91

92

93

94

95

96

97

98

99

100

101

102

103

104

105

106

107

108

109

110

111

112

113

114 digestive abilities predict that the smaller sex will spend more time foraging and less time resting and digesting than the larger sex (Ruckstuhl 1999; Ruckstuhl 1998), such that females will congregate to engage in foraging together while males rest in areas with low risk of predation. A fourth, and much less studied hypothesis is the Weather Sensitivity Hypothesis which suggests that animals could differ in their weather sensitivity (e.g. Young \& Isbell 1991), where larger individuals, often males, suffer higher absolute heat loss and therefore opt for warmer habitats often at the expense of foraging availability (Conradt et al. 2001)

There is little consensus as to what are the driving mechanisms underpinning sexual segregation (Conradt \& Roper 2000; Ruckstuhl et al. 2006). Typically, studies are unable to tease apart which hypothesis best predicts why species segregate, often suggesting that multiple hypotheses could be the cause (Alves et al. 2013; Bonenfant et al. 2007; Loe et al. 2006). One reason for this could be that much of the research concentrates on ungulates (Alves et al. 2013; Bon \& Campan 1996; Bowyer \& Kie 2004), in particular ruminants (Bowyer \& Kie 2004) in systems that are notoriously difficult to study in the wild (Michelena et al. 2004). It is not always feasible in such free-ranging mammalian systems to collect the physiological and behavioural data necessary to explicitly separate and test these competing hypotheses. Furthermore, in some study locations, their natural predators have disappeared, rendering it difficult to explore the effects of predation risk. Finally, many species that have been studied are dietary specialists, meaning that variations in diet quality may chiefly depend on differences between particular plants, even those of the same species, and thus dietary intake is difficult to determine accurately without measuring the nutrient quality of each mouthful (Dove \& Mayes 1996).

The pheasant, Phasianus colchicus, provides a novel, alternative system to ungulates to try to tease apart hypotheses of segregation based on sexual size dimorphism. Many avian species sexually segregate (e.g. northern giant petrels (Macronectes halli) (González-Solís et al. 2000) and Great bustards (Otis tarda) (Palacín et al. 2009)), however such segregation is often attributed to differential settlement of the sexes in discrete habitats, often over large distances, and is primarily explained by and manifest in differences in migration behaviours or broad 
115 differences in habitat use (Catry et al. 2006). Pheasants, however, exhibit a pattern of fine scale

116 sexual segregation similar to the regularly studied ungulate, in that they segregate, outside of the

117 mating season, within the same area as each other (Hill \& Ridley 1987; Whiteside et al. 2018).

118 Specifically, during the late autumn and winter, females aggregate in same sex groups whereas

119 males avoid both males and females (Whiteside et al. 2018). Such segregation persists until early

120 March (Hill \& Ridley 1987; Hill \& Robertson 1988) when harems of females visit and

121 eventually join territory-holding males, which likely reduces their harassment by other males

122 (Ridley and Hill 1987) and allows females to decrease their vigilance levels and so increase time 123 spent foraging (Whiteside et al. 2016a), until they independently start to nest and incubate their

124 eggs (Taber 1949). Pheasants become sexually dimorphic by three weeks of age (Whiteside et al.

125 2017), and chicks in captivity (<8 weeks old) exhibit preference for their own sex (Whiteside et

126 al. 2017). As adults, males have highly conspicuous plumage and are 40\% larger than the cryptic

127 females (Wittzell 1991). Between October and February, before the breeding season, released

128 first year pheasants show increasing levels of segregation (Whiteside et al. 2018). Therefore,

129 pheasants present a system that is analogous to the currently studied ungulates, yet this novel

130 taxa may offer more general insights as to how size-dimorphism may influence sexual

131 segregation for species with fine scale sexual segregation.

132

Mechanisms that drive sexual segregation of pheasants are poorly understood. In the wild, sexual segregation of adults was observed at both a spatial and temporal scale that could not be explained by crude measures of habitat structure, although the homogenous nature of the study and reliance on data from supplementary feeding sites meant that fine scale differences in habitat structure may have not been captured (Whiteside et al. 2018). During early life when the sexes differ little in their size, juvenile pheasants reared in captivity in an environment that controlled for habitat selection and diet, albeit under unnaturally high numbers but at a sex ratio analogous to that observed in the wild, exhibited strong preferences for same-sex individuals in binary choices which may drive segregation (Whiteside et al. 2017). We suggested that at this stage, females aggregate with other females in response to male aggression. When adults, bodysize dimorphism is more pronounced and the habitat is more heterogeneous and consequently we may find other factors influence sexual segregation. We excluded the possibility that segregation 
146 typically spend the majority of their time in hedgerows (Hill \& Robertson 1988), a place that

147 offers both protection from the weather and a high abundance of natural forage (e.g. insects, 148 leaves, berries, wild fruit and nuts Lachlan \& Bray 1973). This violates a major assumption of

149 the Weather Sensitivity Hypothesis in that a habitat should offer either shelter or good foraging 150 opportunity, not both. Therefore, in this study we tested the remaining three main hypotheses for

151

152

153

154

155

156

157

158

159

160

161

162

163

164

165

166

167

168

169

170

171

172

173

174

175

Firstly, pheasants are at risk from terrestrial predators, such as the fox, Vulpes vulpes (Hessler et al. 1970; Krauss et al. 1987), and aerial predators, such as goshawks, Accipter gentilis, sparrow hawks, Accipiter nicus, and buzzards, Buteo buteo, (Kenward et al. 2001; Kenward et al. 1981) resulting in high mortality rates of up to $80 \%$ in the first month after release into the wild (Hessler et al. 1970). Such predation risk is unlikely to explain segregation due to risk aversion by females caring for young because segregation occurs prior to the first breeding season (Hill \& Ridley 1987; Whiteside et al. 2018). However, outside the breeding season, males may still opt for a riskier foraging and movement strategy if there is a benefit for their growth. Therefore, if the Predation Risk Hypothesis influences segregation then we expect that predation risk (in terms of willingness to approach an area where predators have recently visited) and consequently predation rates will differ between sexes.

Secondly, adult pheasants are dietary generalists (Hoodless et al. 2001). Dietary choices can be assayed post-mortem from food that is well preserved and identifiable in the crop of birds that have been shot during recreational hunting (Whiteside et al. 2015). Post-mortem analyses of these shot birds also allows for the measurements of gut morphometrics. Both these factors permit explicit testing of the Forage Selection Hypothesis. While gut size is likely to co-vary with body size, with larger males possessing larger guts, allometric differences are meaningful from a nutritional point of view as larger guts are more effective digesters and absorbers of low quality diet (Barboza \& Bowyer 2000). In addition, body size dimorphisms may correspond to differences in food processing efficiency via bite size (Illius \& Gordon 1987) or grinding capacity in the gizzard (Putaala \& Hissa 1995). If the Forage Selection Hypothesis influences segregation then we expect that the larger sex (males in the case of pheasants) will have larger 
176 guts and heavier gizzards, and this will be matched by a difference in diet corresponding to

177 spatial or temporal segregation.

178

179

180

181

182

183

184

185

186

187

188

189

190

191

192

193

194

195

196

197

198

199

200

201

202

203

204

205

206

Thirdly, differences in behaviour between the sexes in this large, diurnal and conspicuous species have been observed during the breeding season (Whiteside, Langley et al 2016), however little is known about behavioural differences outside the breeding season during the period when pheasants sexually segregate. If the Activity Budget Hypothesis operates then we expect that during the periods of sexual segregation male and female pheasants will differ in their behaviour, specifically state behaviours known to influence sexual segregation in ungulates (e.g. foraging, locomotion or resting time (Ruckstuhl 1998)). Male pheasant chicks in captivity were more aggressive than females and this aggression provides potential mechanisms driving segregation (Whiteside et al. 2017). However, pheasants in the wild exhibit little aggression during the periods that they sexually segregate, with male-male aggression rising from the start of the breeding season and peaking mid-breeding season (Ridley 1983).

To tease apart these hypotheses we draw on two populations of individually identifiable pheasants that were reared in captivity, measured and then released into the wild (see Table 1 for a description of each population and what was measured). The first population was released into an environment that did not have predator control or recreational shooting. Although initial release density was unnaturally high ( 200 birds in a 0.5 Ha release pen), after one month birds had dispersed across the study site. At this point the population density was $\sim 40 \mathrm{birds} / \mathrm{km}^{2}$ which matched those of wild populations, falling within the density (16-54 birds $/ \mathrm{km}^{2}$ ) for wild pheasants living in managed farmland in Austria and the density (0.6-64 birds $/ \mathrm{km}^{2}$ ) for pheasants in their native range in China (Li 1996 in Johnsgard 1999). Crucially, within one month of release this population showed clear sexual segregation which became pronounced as the year progressed (see Whiteside et al. 2018). Releasing on sites without either predator control or recreational hunting allowed us to measure natural predation rates. By using a system of motion sensitive camera traps at feeding sites we were able to determine: 1) if pheasants avoid areas where foxes had been present: and 2) if sexes differ in their willingness to enter an area where a fox had previously been seen (essential for the PRH). The second population were birds that were reared in captivity and released into the wild in large numbers ( $~ 350$ birds in a 0.5 Ha release pen) as part of a 
207 restocking programme for commercial shooting. However, these birds were released on a much

208 larger site and within a few weeks of birds dispersing resulted in much lower density over the 209 entire estate. On this site there was managed predator control and the birds were subject to

210 hunting. Birds released using this method still show patterns of sexual segregation (Hill \& Ridley

211 1987) similar to that observed in pheasants released at lower density. Releasing onto a site that

212 has recreational hunting allows for us to conduct post mortem analysis that: 1) allows us to

213 determine the extent of sexual dimorphism in body size (essential for PRH, FSH and ABH) and

214 in gut morphology (essential for FSH); and 2) acts as a dietary snapshot, whereby crop sample

215 analyses allows us to determine diet (essential for FSH). Observing behaviour of pheasants

216 during this period allows us to determine activity budgets (essential for ABH).

217

218 Material and methods

219

220

Rearing

221

222

In May 2012 and 2013 we reared 1800 pheasants (900 / year) from one day old as part of

223 a long-term study to determine how early rearing conditions can influence development and post release mortality. Chicks were placed in houses of 30 individuals with an equal sex ratio and each house was randomly allocated a rearing treatment. While not relevant to this study, the treatments included differences in supplemented diet in 2012 (see Table 1 and Whiteside et al. 2015) and access to perches in 2013 (see Table 1 and Whiteside et al. 2016b) as well as controls. In 2014 and 2015 we reared a further 400 pheasants (200 / year) from one day old and housed them in groups of 50 under identical conditions (see Table 1). Each year the birds were housed for two weeks in heated sheds (2012/13: $1.3 \mathrm{~m} \mathrm{x} 1.3 \mathrm{~m} ; 2014 / 15: 2 \mathrm{~m} \times 2 \mathrm{~m})$ and were then given access to an additional open grass run $(2012 / 13=1.3 \mathrm{~m}$ x $6.8 \mathrm{~m} ; 2014 / 15: 4 \mathrm{~m} \times 12 \mathrm{~m})$ until release. All chicks were provided with age specific commercial chick crumbs (Sportsman Game Feeds) ad lib and in excess. Water was provided ad lib. In all four years, birds were marked with patagial wing tags (Roxan Ltd, Selkirk, UK) for identification with additional white PVC wing tags $(25 \mathrm{~mm} \times 75 \mathrm{~mm})$ with individually unique identifying numbers which could be viewed from several tens of meters away. 
238

239

240

241

242

243

244

245

246

247

248

249

250

251

252

253

254

255

256

257

258

259

260

261

262

263

264

265

266

267

268

Release into the wild

Following rearing, birds were randomly mixed from across different housing groups and placed into open topped pens. Release pens typically consisted of wire mesh fences $\sim 2 \mathrm{~m}$ high enclosing an extensive area of woodland (GWCT 1991). In these pens birds were provided with food and water $a d$ lib. Birds could disperse from these pens and were free to roam and mix with other released, as well as resident, pheasants. In 2012 and 2013 when birds were approximately seven weeks old we released them onto the Middleton Estate, Hampshire, UK $\left(51^{0} 18^{\prime} \mathrm{N}, 1^{0} 4^{\prime} \mathrm{W}\right)$. The estate, predominantly arable, hosts a game shoot and employs two game keepers to manage the released pheasants through habitat management, providing supplementary food, and controlling predator numbers. Between October and February birds were shot as part of a recreational shoot. In 2014 and 2015 when birds were ten weeks old they were released at North Wyke Farm, Devon $\left(50^{0} 77^{\prime} \mathrm{N}, 3^{0} 9^{\prime} \mathrm{W}\right)$. This site is grazed by cattle and sheep and no game shooting or predator control occurred there. Forty feeders, filled with wheat, were placed within the pen $(n=4)$ and in the surrounding countryside $(n=36)$ at a density of 0.16 per hectare. In 2014, each feeder was continuously monitored with Bushnell@ Trophy motion activated cameras. All animals that visited a feeder and its surrounding area were photographed and the images were then viewed manually to record the time that pheasants and foxes visited the feeder site. Individual pheasants could be identified from their wing tag numbers.

\section{Body size dimorphism}

We recorded the mass (Slater Super Samson spring balance - precision $5 \mathrm{~g}$ ) and tarsus length (precision $1 \mathrm{~mm}$ ) of all birds upon release into the wild and for birds released in 2012 and 2013 we scored the same measures within four hours of them being shot which occurred four to seven months after their release.

For the released populations we used a General Linear Mixed Model (GLMM) to identify whether males differed from females in their mass and tarsus length with rearing treatment and sex as fixed factors and the rearing house as a random factor, with all two way interactions included (Table 2). In 2014 and 2015 all birds were reared under identical conditions and 
269 therefore rearing treatment was not included in the model. For birds shot in 2012 and 2013 a

270 General Linear Model (GLM) was used to ask if sexes differed in mass and tarsus length as

271 adults. The bird's age when shot, its rearing treatment and all two way interactions were included

272 in the GLM (Table 2).

273

274

275

276

277

278

279

280

281

282

283

284

285

286

287

288

289

290

291

292

293

294

295

296

297

298

299

A test for the Predation Risk Hypothesis: First appearance at a feeder after the presence of a fox

We recorded every sighting of a fox and pheasant at each of our feeder sites during December 2014 and January 2015 using the motion camera traps. In order to test whether the presence of foxes at feeders was an indicator of a risky environment that pheasants attended to, we tested whether birds took longer to return to feeders after a fox had been there compared to the time it took them to appear at a feeder after a time-matched control point the previous day. We excluded instances where there were low visitation rates at a feeder, indicated by long periods ( $>420$ mins) between the time-matched control point and the first pheasant appearing. This cut-off point was meaningful and discrete (Figure 1). This left a subset of the previous data including 110 cases. We used a t-test to ask if pheasants took longer to approach a feeder if it had been visited by a fox compared a time matched control point the previous day. We then looked at each appearance of a fox and recorded the sex of the next pheasant to enter the same feeder within a subsequent 30 minutes. We used a binomial test to determine if sexes differed in their likelihood of approaching a feeder following a fox visit.

\section{A test for the Predation Risk Hypothesis: Do predation rates differ with sex}

In 2012 and 2013 we conducted searches of areas surrounding the release site to retrieve birds that had been killed by predators. Searches were conducted daily from August-October and then again in February. During the hunting season (late October to February) the area was visited less frequently but more methodically by beaters who were engaged in driving the game to the waiting hunters. They were informed of the project and searched for carcases and tags as they walked through the site. In 2015 we collected birds that had been killed by a predator by searching the release site and surrounding areas for carcases, locating these either directly or 
300

301

302

303

304

305

306

307

308

309

310

311

312

313

314

315

316

317

318

319

320

321

322

323

324

325

326

327

328

329

330

guided by radio tags placed on 50 birds. In 2014 we did not conduct detailed searches for carcases. A binomial test was used to test whether predation numbers differed between sexes with the expected outcome based on the released sex ratio.

\section{A test for Forage Selection Hypothesis: Measuring gut morphology}

We collected linear gut measures (oesophagus, intestine, colon and ceca) and gut masses (oesophagus, intestine, crop, gizzard and ceca; for methods see Leopold 1953) of 186 birds shot in 2012. Ceca length and ceca mass were calculated as the average for both ceca. Gizzard volume was measured as the height multiplied by width. We used a GLM to test whether gut morphologies differed with sex. Since rearing treatment can influence gut morphology (Whiteside et al. 2015) we included the rearing treatment and the age at which the bird was shot as fixed factors (Table 2).

\section{A test for Forage Selection Hypothesis: Measuring crop contents in the wild}

In 2012, we removed the crops of 159 shot birds and measured the mass before and after removal of its contents. Measures were transformed using the $\sqrt{ }(x)$ transformation to meet assumptions of normality and then a GLM was used to test if mass of crop content differed between males and females. In 2013, we emptied the crops of 168 shot birds and quantified their contents. We used a GLM to ask whether males differed from females in the number of different food items discovered in their crops. Diet availability will change depending on when the bird is shot and diet choice is influenced by rearing treatment (Whiteside et al. 2015) therefore in both GLMs we included rearing treatment and the age of the bird when it was shot in the model (Table 2). We separated all known items into common food categories (Wheat, Maize, Grass, Oil Seed Rape, Insects, Seeds, Galls, Acorns) and used binomial tests to determine if sexes differed in the likelihood of their crop containing food of each category.

\section{A test for Activity Budget Hypothesis: Measuring behaviour in the wild}


331

332

333

334

335

336

337

338

339

340

341

342

343

344

345

346

347

348

349

350

351

352

353

354

355

356

357

358

359

360

361

In 2012, we conducted continuous focal follows, for a maximum of 10 minutes, observing 167 released pheasants between 18 September and 5 November. All observations were conducted from inside a vehicle at a distance of $>10 \mathrm{~m}$ (e.g. Whiteside et al. 2016a) either during the first 2 hours after first light or the final 2 hours before last light (Taber 1949). We recorded the total time we observed the birds, the time spent foraging and the number of foraging bouts they performed. A foraging bout began with the lowering of the head and neck towards the ground and ended when the neck was raised. The proportion of time an animal spent foraging was normalised using a logit transformation: $\log (\mathrm{y} / 1-\mathrm{y})$ (Warton \& Hui 2010) and a GLM was used to test if the percentage of time spent foraging differed between the sexes.

In 2013, between 15 August and 16 September we conducted a series of 10 minute focal follows with an instantaneous point sampling procedure at 30 second intervals on 214 pheasants. This allowed us to collect state behaviours; in particular time spent performing resting, foraging and locomotive behaviours and also aggressive interactions. All birds were identifiable from their wing tags and were observed from a distance so as to not disturb their natural behaviours. Vigilance was described as sitting or standing with neck extended and eyes open. Resting was determined as either standing or lying with eyes closed. Aggressive interactions included threats, run threats, lateral struts and fights (see Hill \& Robertson 1988; Ridley 1983).We used a Generalised Linear Model with a binomial distribution and a probit link function to ask if sexes differed in their vigilance, walking and resting likelihoods. In all models early rearing environment, time of day (AM or PM), and degree of aerial protection (open or closed) were included as fixed factors, and all two-way interactions were assessed (Table 2).

\section{Statistical Analyses}

All GLM and GLMM analyses were conducted using SPSS v23. All models were visually inspected for homogeneity of variance, normality of error and linearity.

\section{Ethical Statement}

All birds were reared using commercial procedures that adhere to the DEFRA Code of Practice for the Welfare of Game Birds Reared for Sporting Purposes (DEFRA 2009). During 
362 rearing, minimal handling was used for obtaining morphometrics and placing birds in testing 363 chambers. In 2012 and 2013, once birds dispersed from the release pen, gamekeepers supplied 364 supplementary feed and water, which was reduced after the shooting season (from $1^{\text {st }}$ February).

365 The birds were shot as a part of a commercial shoot, and were not specifically shot for this study.

366 In 2014 and 2015 released birds were attended to by the authors and there was no shooting on the 367 study site. The work was approved by the University of Exeter Psychology Ethics Committee 368 and conducted under Home Office licences number PPL 30/3204 \& PPL 30/2942

369

370

371

372

373

374

375

376

377

378

379

380

381

382

383

384

385

386

387

388

389

390

391

392

\section{RESULTS}

Are birds sexually dimorphic during the period of the study?

Males were significantly heavier (Table 3) and had longer tarsi (Table 4) than females upon release into the wild and when they were shot as adults prior to their first breeding season

A test for the Predation Risk Hypothesis: Do sexes differ in their likelihood of being the first to approach a feeder visited by a fox?

Pheasants took significantly longer (approx. 2.5 times longer) to appear at a feeder after a fox was present $(193 \pm 35 \mathrm{mins})$ than after a time-matched control point the previous day (76 \pm 9 mins $)\left(\mathrm{t}_{109}=3.37, \mathrm{P}=0.001\right.$, Figure 2$)$. There was no difference in the likelihood that a male or female would be first to approach a feeding site in the following 30 minutes after the sighting of a fox (female $=20$; male $=30$; Binomial test: $P=0.20$ ).

A test for Predation Risk Hypothesis: Do predation rates differ with sex?

Predation did not differ with sex in the first 8 months after release in 2012 (Binomial tests: 2012 : female $=8 ;$ male $=5, P=0.58$ ); 2013 (Binomial test: female $=6$; male $=12: P=$ 0.20); and 2015 (Binomial test: female $=15$; male $=27: P=0.12$ ).

A test for Forage Selection Hypothesis: Do sexes differ in their gut morphology? 
393

394

395

396

397

398

399

400

401

402

403

404

405

406

407

408

409

410

411

412

413

414

415

416

417

418

419

420

421

422

423

Males significantly differed from females in all aspects of measured gut morphologies with larger and heavier gut regions, crops and gizzards (Table 5).

A test for Forage Selection Hypothesis: Does diet composition differ between sexes?

Males $(17.38 \mathrm{~g} \pm 1.62)$ shot in 2012 had significantly more forage in their crops compared to females $(12.75 \mathrm{~g} \pm 1.08)\left(\mathrm{F}_{1,131}=4.29, P=0.040\right.$, Figure 3$)$. However, males $(3.33 \pm 0.16)$ did not differ from females $(3.52 \pm 0.27)$ in the variety of food items found within their crop $\left(\mathrm{F}_{1,147}=\right.$ $0.93, P=0.34)$. The sexes appeared to utilise a similar diet with both sexes carrying similar proportions of eight common food types in their crops. Males did not differ from females in the likelihood that their crop would contain wheat, maize, grass, oil seed rape, insects, seeds, galls or acorns (Table 6).

A test for Activity Budget Hypothesis: Do other behaviour differ between sexes?

Sexes did not differ in their percentage of time spent foraging; the length of each foraging bout (Table 7); their likelihood of being vigilant $\left(\mathrm{F}_{1,186}=0.20, P=0.66\right)$ or their likelihood of walking $\left(\mathrm{F}_{1,186}=2.54, P=0.13\right)$. There was only one incidence of resting behaviour during the focal watches which was demonstrated by a male and there were no aggressive interactions performed hence sex differences in these behaviours could not be compared.

\section{DISCUSSION}

During the late autumn and winter, when pheasants show an increased tendency to sexually segregate (Whiteside et al. 2018), pheasants exhibited strong sexual size dimorphism. Adult males were significantly heavier than females and had larger gut dynamics and heavier gizzards, however, we found little evidence that sexes differed in behavioural and dietary measures that are predicted to explain sexual segregation that we observed according to the three existing hypotheses purporting to explain segregation due to size dimorphism (Bleich et al. 1997; Bonenfant et al. 2007; Conradt 1998; Ruckstuhl 1998). 
Males pheasants were $1.3 \mathrm{x}$ heavier than females which is similar to levels of dimorphism

426

427

428

429

430

431

432

433

434

435

436

437

438

439

440

441

442

443

444

445

446

447

448

449

450

451

452

453

454

Pheasants may reduce their risk of predation by avoiding feeders recently visited by foxes. This was indicated by their increasing the lag between feeder visitations after a fox visit compared to a time-matched control point the previous day, suggesting that time taken to visit a feeder after a fox has been there provided a good assay of risk sensitivity. However, we found that sexes did not differ in their exposure to fox predation risk, at least at feeders, indicated by their likelihood of being the first bird to visit a feeding site after a fox had been present. Such patterns of risk sensitivity may differ at non-feeding sites. A better understanding of concurrent predator and pheasant movement would also help clarify how predator risk might influence segregation. This similarity between the sexes in their willingness to enter an area previously visited by a fox, the most common predator of pheasants in the UK, may explain why we also found no significant differences in predation rates between sexes across all three years in which we monitored predation. This may appear somewhat surprising, particularly if the size and colouration of males makes them more conspicuous and indeed we tended to find more males predated than females, perhaps because we used visual searches favouring detection of the larger and more visible males. However, other studies using radio collared release populations, also revealed no differences in predation rates between sexes (Musil \& Connelly 2009; Turner 2007). In contrast to the breeding season when nesting females are more exposed to foxes either while sitting on the nest or attending dependent young, pheasants of both sexes faced similar predation risks and suffered similar predation rates during autumn/winter prior to the breeding season. During this period females may not discriminate against high predation risk habitats because 
455 they do not have to protect their young. In contrast, immediately after the breeding season,

456 precocial pheasant chicks frequently stay with their mother for over 28 days (Riley et al. 1998)

457 and during this time (June-August) females with young may occupy low risk habitats. However,

458 our recording periods did not encompass this time and our females were all birds hatched in the

459 spring and therefore had not yet bred. The similarity between the sexes in predation risk and

460 consequent predation rates suggests that the Predation Risk Hypothesis may not adequately

461 account for sexual segregation in pheasants outside the breeding season.

462

463

During the period that pheasants sexually segregate, females were smaller in both body

464

465

466

467

468

469

470

471

472

473

474

475

476

477

478

479

480

481

482

483

484

485

size and in all aspects of their gut morphology. The longer intestinal system in male pheasants suggests a better ability to efficiently digest a lower quality diet (Moss 1983). Larger gizzards in the males also suggest a more effective grinding mechanism, perhaps allowing the digestion of harder food items (Putaala \& Hissa 1995). Such gastro-intestinal dimorphism is common in sexually segregating ungulates, often with males having a larger rumen, small intestine and colon, allowing for them to forage on much less digestible forage (Barboza \& Bowyer 2000). Such differences in morphologies could cause sexes to differ in their diet, perhaps with female pheasants choosing higher quality foods which are easy to grind in the gizzard. However, we did not observe differences in crop content when considering a suite of common food items.

Similarity in dietary preference was also observed in pheasants when tested as chicks in captivity and presented with a choice of a variety of natural and man-made food items (Whiteside et al. 2017). Dietary difference between sexes often occurs, or become more pronounced, in periods leading up to nesting and incubation (Lewis et al. 2002; Nisbet 1997). During the same period that data from this study was collected, the degree of sexual segregation becomes stronger as the pheasants get older (Whiteside et al. 2018). This might indicate that females begin to differentiate their foraging behaviours more in the run up to the start of the breeding season in March. Our sampling of crop contents finished at the start of February corresponding with the end of the shooting season, so we may have missed this dietary switch at the advent of the breeding season. Although dimorphic in gastro-intestinal morphology, our findings that sexes do not differ in dietary breadth or composition suggest that the Forage Selection Hypothesis may not adequately explain pheasant sexual segregation witnessed during the pre-breeding period. 
486

487

488

489

490

491

492

493

494

495

496

497

498

499

500

501

502

503

504

505

506

507

508

509

510

511

512

513

514

515

516

Nutrient intake requirements are proportional to body size for many species (Demment \& Van Soest 1985), yet we found the dietary breadth and composition was similar for both sexes of pheasants (see above). Therefore, we predicted that males would forage more than females, while exhibiting correspondingly lower levels of alternative behaviours such as walking or vigilance, leading to segregation. However we found that males and female pheasants did not differ in their proportion of time spent foraging. One explanation is that there is a sex difference in foraging efficiency and that males can consume enough nutrients in a similar time period. Such an explanation is supported by the observation that male pheasant chicks were twice as quick as females when presented with a novel food handling challenge (Whiteside et al. 2017). A lack of sex differences in foraging has also been observed in desert big horn sheep, Ovis canadensis mexicana, (Mooring et al. 2003) and musk ox, Ovibos moschatus (Côté et al. 1997). In species where sex differences in time spent foraging are observed it is often attributed to their investment in reproduction (Lewis et al. 2002) and differences in parental care roles (Gray \& Hamer 2001; Thaxter et al. 2009). Although female pheasants will forage more than males prior to nesting (Ridley \& Hill 1987; Whiteside et al. 2016a), this occurs in early spring after hens have abandoned their segregated winter aggregations and joined harems.

Much of the post-ingestion processing of foods in pheasants is conducted in the gizzard (Putaala \& Hissa 1995), with coarse material being fermented in the ceca, both of which are smaller in females. Given the consistency in diet between sexes (see above) we predict that females spend longer processing food and thus may be observed resting for longer. However, unlike in some sexually dimorphic ruminants (Ruckstuhl \& Neuhaus 2002) we found that males did not differ from females in the likelihood that they would be resting, hence suggesting that resting activity cannot explain patterns of sexual segregation.

The Activity Budget Hypothesis is not restricted to behaviours related to food processing, as synchrony of other behaviours can also result in aggregation of the same sex. For instance, increased movement rates by females have been suggested as a reason for sexual segregation in big horn sheep (Ruckstuhl 1998). However, we found that male pheasants did not differ from females in their occurrence of walking. Likewise, similar movement patterns across the sexes were observed in merino sheep (Michelena et al. 2004). All locomotor behaviours that we 
517 measured were consistent across sexes, therefore we believe that the Activity Budget Hypothesis

518 fails to predict sexual segregation in pheasants.

519

520

Aggression in adult pheasants is rarely seen between the sexes and male-male aggression

521 is typically restricted to the breeding season, peaking at the end of March (Ridley 1983) and

522 therefore it is not surprising that we observed no aggressive interactions at any of our point

523 samples. Consequently, we can, tentatively, reject aggression as a potential behavioural

524 mechanism driving sexual segregation. This contrasts with what we observed in young pheasants

525 in captivity where high levels of aggression was observed in males (Whiteside et al. 2017), and

526 perhaps a memory of these effects can persist over the following months driving segregation

527 post-release. However, this does not explain why the level of segregation becomes stronger over

528 time. Our use of state behaviour recording in this study may have missed sporadic but important

529 aggressive interactions, so if we suspect that segregation is driven by one sex trying to avoid

530 aggression by the other a more detailed recording of aggression is required.

531

532

It is important to acknowledge the limitation of using captive-reared pheasants as a model

533

system to help understand sexual segregation. Firstly, they are reared in an unnatural

534

environment. Whilst an artificial rearing environment allows us to control for important factors

535

like experience (e.g. of diet, predators) it may also distort future social dynamics due to the lack

536

of adult role models and a relatively limited and barren physical environment. Secondly, the

537

pheasants are released at high densities, initially much greater than that of natural populations,

and this could influence availability of habitat or forage. However, such both wild and artificially

539

reared pheasants exhibit sexual segregation post release (Hill \& Ridley 1987; Ridley 1983;

540 Whiteside et al. 2018), although we cannot confirm that the drivers of segregation match those of

541 truly wild birds. Confirmation would require a similarly detailed study on a wild population

542 where predators could be observed and gut morphology and contents recorded.

543

544

Sexual dimorphism is fundamental to a suite of hypotheses that predict why many

545 species, mainly ungulates, sexually segregate at a fine scale (Pérez-Barbería \& Gordon 1999).

546 However, although size (and plumage) dimorphism is also observed and pronounced in

547 pheasants, we found that the sexes did not differ in their predation risk, diet or behaviour. We 
548 therefore found no support that the Predation Risk, Forage Selection or Activity Budget

549 hypotheses adequately explain sexual segregation of pheasants outside the breeding season. We 550 can conceive of four explanations for this. First, birds (including pheasants) exhibit highly plastic 551 gastro-intestinal systems in order to reduce excess mass which is costly to flight (Dudley \& 552 Vermeij 1992; Gasaway 1976; Whiteside et al. 2015). This flexibility may mean that gut size, 553 and hence the efficiency of nutrient absorption which underpins the hypotheses we tested, is not 554 as closely linked to body size as in ungulates. Consequently, the differences we observe in body 555 size in pheasants do not match differences in dietary needs or foraging patterns and so do not 556 lead to a segregation of the sexes. Second, segregation may be driven by other inherent, social, 557 factors. Pheasants younger than those tested in this paper prefer to associate with others of the 558 same sex in binary choice tests, perhaps because males are aggressive and so seek out same sex 559 partners to spar with, or because females actively avoid males that may injure them (Whiteside et 560 al. 2017). Such preferences developed early in life may persist into early adulthood, even though 561 the adults look markedly different from the appearance of the chicks that we tested. Female 562 pheasants older than those tested in this paper also prefer to associate other females in binary 563 choice tests (Madden \& Whiteside 2013). We have not explicitly tested the social preferences of 564 pheasants at the ages we studied in this current paper and we advise this for future work.

565 Alternatively, sexes may socially segregate because they are attracted to each other (Social 566 Attraction Hypothesis), in order to facilitate social learning or to become less conspicuous to 567 predators (Croft et al. 2003; Lingle 2001). Further work is required to explore what, if any, 568 benefits pheasants gain from same-sex social partners. Third, segregation may be due to an 569 attempt to reduce risks of infection by females because sexually dimorphic males can carry 570 higher parasite burdens and avoiding them may lower the risk of transmission (Ferrari et al. 571 2010; Perkins et al. 2003). We did not measure parasite loads of pheasants. Finally, although we 572 explicitly tested the hypotheses in isolation, some or all of them may influence or reinforce 573 segregation in conjunction with one another. For example, subtle initial differences in diet 574 preferences may initially lead to same sex aggregations (Forage Selection Hypothesis) in which 575 the sexes learn improved foraging techniques from one another (Social Attraction Hypothesis), 576 which leads to synchronised exploitation of specific food types (Activity Budget Hypothesis).

577 Understanding why the sexes segregate may require a more nuanced and integrative 578 consideration of the current hypotheses. 


\section{References}

582

583

584

585

586

587

588

589

590

591

592

593

594

595

596

597

598

599

600

601

602

603

604

605

606

607

608

609

610

611

612

613

614

615

616

617

618

619

620

621

622

623

624
Alonso JC, Magaña M, Alonso JA, Palacín C, Martín CA, and Martín B. 2009. The most extreme sexual size dimorphism among birds: allometry, selection, and early juvenile development in the great bustard (Otis tarda). The Auk 126:657-665.

Alves J, da Silva AA, Soares AM, and Fonseca C. 2013. Sexual segregation in red deer: is social behaviour more important than habitat preferences? Animal Behaviour 85:501-509.

Barboza PS, and Bowyer RT. 2000. Sexual segregation in dimorphic deer: a new gastrocentric hypothesis. Journal of Mammalogy 81:473-489.

Barboza PS, and Bowyer RT. 2001. Seasonality of sexual segregation in dimorphic deer: extending the gastrocentric model. Alces 37:275-292.

Bleich VC, Bowyer RT, and Wehausen JD. 1997. Sexual segregation in mountain sheep: resources or predation? Wildlife Monographs:3-50.

Blood DA, Flook DR, and Wishart WD. 1970. Weights and growth of Rocky Mountain bighorn sheep in western Alberta. The Journal of Wildlife Management:451-455.

Bon R, and Campan R. 1996. Unexplained sexual segregation in polygamous ungulates: a defense of an ontogenetic approach. Behavioural Processes 38:131-154.

Bonenfant C, Gaillard J-M, Dray S, Loison A, Royer M, and Chessel D. 2007. Testing sexual segregation and aggregation: old ways are best. Ecology 88:3202-3208.

Bowyer RT. 2004. Sexual segregation in ruminants: definitions, hypotheses, and implications for conservation and management. Journal of Mammalogy 85:1039-1052.

Bowyer RT, and Kie JG. 2004. Effects of foraging activity on sexual segregation in mule deer. Journal of Mammalogy 85:498-504.

Catry P, Phillips RA, Croxall JP, Ruckstuhl K, and Neuhaus P. 2006. Sexual segregation in birds: patterns, processes and implications for conservation. Sexual segregation in vertebrates: ecology of the two sexes:351-378.

Clutton-Brock TH. 1989. Review lecture: mammalian mating systems. Proceedings of the Royal Society of London B: Biological Sciences 236:339-372.

Clutton-Brock TH, Guinness FE, and Albon S. 1982. Red deer: behavior and ecology of two sexes: University of Chicago Press.

Conradt L. 1998. Could asynchrony in activity between the sexes cause intersexual social segregation in ruminants? Proceedings of the Royal Society of London B: Biological Sciences 265:1359-1368.

Conradt L, Gordon I, Clutton-Brock T, Thomson D, and Guinness F. 2001. Could the indirect competition hypothesis explain inter-sexual site segregation in red deer (Cervus elaphus L.)? Journal of Zoology 254:185-193.

Conradt L, and Roper T. 2000. Activity synchrony and social cohesion: a fission-fusion model. Proceedings of the Royal Society of London B: Biological Sciences 267:2213-2218.

Corti $P$, and Shackleton DM. 2002. Relationship between predation-risk factors and sexual segregation in Dall's sheep (Ovis dalli dalli). Canadian Journal of Zoology 80:2108-2117.

Côté SD, Schaefer JA, and Messier F. 1997. Time budgets and synchrony of activities in muskoxen: the influence of sex, age, and season. Canadian Journal of Zoology 75:1628-1635.

Croft DP, Arrowsmith B, Bielby J, Skinner K, White E, Couzin ID, Magurran AE, Ramnarine I, and Krause J. 2003. Mechanisms underlying shoal composition in the Trinidadian guppy, Poecilia reticulata. Oikos 100:429-438. 
625

626

627

628

629

630

631

632

633

634

635

636

637

638

639

640

641

642

643

644

645

646

647

648

649

650

651

652

653

654

655

656

657

658

659

660

661

662

663

664

665

666

667

668

669

670

671

672

DEFRA. 2009. Code of practice for the welfare of game birdsreared for sporting purposes. In: Department for Environment FaRA, editor: Department for Environment, Food and Rural Affairs. Demment M. 1982. The scaling of ruminoreticulum size with body weight in East African ungulates. African Journal of Ecology 20:43-47.

Demment MW, and Van Soest PJ. 1985. A nutritional explanation for body-size patterns of ruminant and nonruminant herbivores. American Naturalist:641-672.

Dove H, and Mayes R. 1996. Plant wax components: a new approach to estimating intake and diet composition in herbivores. The journal of nutrition 126:13.

Dudley R, and Vermeij G. 1992. Do the power requirements of flapping flight constrain folivory in flying animals? Functional Ecology 6:101-104.

Ferrari N, Rosà R, Lanfranchi P, and Ruckstuhl KE. 2010. Effect of sexual segregation on host-parasite interaction: Model simulation for abomasal parasite dynamics in alpine ibex (Capraibex). International Journal for Parasitology 40:1285-1293. https://doi.org/10.1016/j.ijpara.2010.03.015

Gasaway WC. 1976. Seasonal variation in diet, volatile fatty acid production and size of the cecum of rock ptarmigan. Comparative Biochemistry and Physiology Part A: Physiology 53:109-114. http://dx.doi.org/10.1016/S0300-9629(76)80021-7

González-Solís J, Croxall JP, and Wood AG. 2000. Sexual dimorphism and sexual segregation in foraging strategies of northern giant petrels, Macronectes halli, during incubation. Oikos 90:390-398. 10.1034/j.1600-0706.2000.900220.x

González-Solís J. 2004. Sexual size dimorphism in northern giant petrels: ecological correlates and scaling. Oikos 105:247-254.

Gray CM, and Hamer KC. 2001. Food-provisioning behaviour of male and female Manx shearwaters, Puffinus puffinus. Animal Behaviour 62:117-121.

GWCT. 1991. Gamebird releasing. Fordingbridge, Hampshire: Game and Wildlife Conservation Trust.

Hessler E, Tester JR, Siniff DB, and Nelson MM. 1970. A biotelemetery study of survival of pen-reared pheasants released in selected habitats. The Journal of Wildlife Management 34:267-274.

Hill DA, and Ridley MW. 1987. Sexual segregation in winter, spring dispersal and habitat use in the pheasant (Phasianus colchicus). Journal of Zoology 212:657-668.

Hill DA, and Robertson PA. 1988. The pheasant: ecology, management and conservation. Oxford: Blackwell Scientific Books.

Hoodless A, Draycott R, Ludiman M, and Robertson P. 2001. Spring foraging behaviour and diet of released pheasants (Phasianus colchicus) in the United Kingdom. Game \& wildlife science 18:375-386.

Illius AW, and Gordon IJ. 1987. The Allometry of Food Intake in Grazing Ruminants. Journal of Animal Ecology 56:989-999. 10.2307/4961

Johnsgard P. 1999. The pheasant of the world: biology and natural history. Washington: Smithsonian Institution Press.

Kenward R, Hall D, Walls S, and Hodder K. 2001. Factors affecting predation by buzzards Buteo buteo on released pheasants Phasianus colchicus. Journal of Applied Ecology 38:813-822.

Kenward RE, Marcström V, and Karlbom M. 1981. Goshawk winter ecology in Swedish pheasant habitats. The Journal of Wildlife Management 45:397-408.

Krauss G, Graves H, and Zervanos S. 1987. Survival of wild and game-farm cock pheasants released in Pennsylvania. The Journal of Wildlife Management 51:555-559.

Lachlan C, and Bray R. 1973. A study of an unmanaged pheasant population at Brownsea Island, Dorset, England. Trans X Int Union Game Biol Congr, Paris. p 609-617.

Leopold AS. 1953. Intestinal morphology of gallinaceous birds in relation to food habits. The Journal of Wildlife Management 17:197-203. 
673

674

675

676

677

678

679

680

681

682

683

684

685

686

687

688

689

690

691

692

693

694

695

696

697

698

699

700

701

702

703

704

705

706

707

708

709

710

711

712

713

714

715

716

717

718

719

720

Lewis S, Benvenuti S, Dall-Antonia L, Griffiths R, Money L, Sherratt T, Wanless S, and Hamer K. 2002. Sex-specific foraging behaviour in a monomorphic seabird. Proceedings of the Royal Society of London B: Biological Sciences 269:1687-1693.

Lingle S. 2001. Anti-predator strategies and grouping patterns in white-tailed deer and mule deer. Ethology 107:295-314.

Loe LE, Irvine RJ, Bonenfant C, Stien A, Langvatn R, Albon SD, Mysterud A, and Stenseth NC. 2006. Testing five hypotheses of sexual segregation in an arctic ungulate. Journal of Animal Ecology 75:485-496.

Lüps P, and Roper T. 1988. Tooth size in the European badger (Meles meles) with special reference to sexual dimorphism, diet and intraspecific aggression. Acta Theriologica 33:21-33.

Madden JR, and Whiteside MA. 2013. Variation in female mate choice and mating success is affected by sex ratio experienced during early life. Animal Behaviour 86:139-142.

Main MB, and Coblentz BE. 1996. Sexual segregation in Rocky Mountain mule deer. The Journal of Wildlife Management:497-507.

Michelena P, Bouquet PM, Dissac A, Fourcassie V, Lauga J, Gerard J-F, and Bon R. 2004. An experimental test of hypotheses explaining social segregation in dimorphic ungulates. Animal Behaviour 68:1371-1380.

Mooring MS, Fitzpatrick TA, Benjamin JE, Fraser IC, Nishihira TT, Reisig DD, and Rominger EM. 2003. Sexual segregation in desert bighorn sheep (Ovis canadensis mexicana). Behaviour 140:183-207.

Moss R. 1983. Gut size, body weight, and digestion of winter foods by grouse and ptarmigan. Condor 85:185-193.

Musil DD, and Connelly JW. 2009. Survival and reproduction of pen-reared vs translocated wild pheasants Phasianus colchicus. Wildlife Biology 15:80-88.

Nisbet IC. 1997. Female Common Terns Sterna hirundo eating mollusc shells: evidence for calcium deficits during egg laying. Ibis 139:400-401.

Palacín C, Alonso JC, Alonso JA, Martín CA, Magaña M, and Martin B. 2009. Differential migration by sex in the great bustard: possible consequences of an extreme sexual size dimorphism. Ethology 115:617-626.

Pérez-Barbería F, and Gordon I. 1999. Body size dimorphism and sexual segregation in polygynous ungulates: an experimental test with Soay sheep. Oecologia 120:258-267.

Perkins SE, Cattadori IM, Tagliapietra V, Rizzoli AP, and Hudson PJ. 2003. Empirical evidence for key hosts in persistence of a tick-borne disease. International Journal for Parasitology 33:909-917.

Prins H. 1989. Condition changes and choice of social environment in African buffalo bulls. Behaviour 108:297-323.

Putaala A, and Hissa R. 1995. Effects of hand-rearing on physiology and anatomy in the grey partridge. Wildlife Biology 1:27-31.

Ridley M. 1983. Mating system of the pheasant (Phasianus colchicus). University of Oxford.

Ridley M, and Hill D. 1987. Social organization in the pheasant (Phasianus colchicus): harem formation, mate selection and the role of mate guarding. Journal of Zoology 211:619-630.

Riley TZ, Clark WR, Ewing E, and Vohs PA. 1998. Survival of Ring-Necked Pheasant Chicks during Brood Rearing. The Journal of Wildlife Management 62:36-44.

Ruckstuhl K. 1999. To synchronise or not to synchronise: a dilemma for young bighorn males? Behaviour 136:805-818.

Ruckstuhl K, Manica A, MacColl A, Pilkington J, and Clutton-Brock T. 2006. The effects of castration, sex ratio and population density on social segregation and habitat use in Soay sheep. Behavioral Ecology and Sociobiology 59:694-703.

Ruckstuhl K, and Neuhaus P. 2002. Sexual segregation in ungulates: a comparative test of three hypotheses. Biological reviews of the Cambridge Philosophical Society 77:77-96. 
721 Ruckstuhl K, and Neuhaus P. 2005. Sexual segregation in vertebrates: Cambridge University Press.

722 Ruckstuhl KE. 1998. Foraging behaviour and sexual segregation in bighorn sheep. Animal Behaviour 723 56:99-106.

724

725

726

727

728

729

730

731

732

733

734

735

736

737

738

739

740

741

742

743

744

745

746

747

748

749

750

751

752

753

754

755

756

757

758

759
Ruckstuhl KE, and Neuhaus P. 2000. Sexual segregation in ungulates: a new approach. Behaviour 137:361-377.

Stoehr AM, and Kokko H. 2006. Sexual dimorphism in immunocompetence: what does life-history theory predict? Behavioral Ecology 17:751-756. 10.1093/beheco/ark018

Taber RD. 1949. Observations on the breeding behavior of the ring-necked pheasant. Condor 51:153175.

Thaxter CB, Daunt F, Hamer KC, Watanuki Y, Harris MP, Grémillet D, Peters G, and Wanless S. 2009. Sex-specific food provisioning in a monomorphic seabird, the common guillemot Uria aalge: nest defence, foraging efficiency or parental effort? Journal of Avian Biology 40:75-84.

Turner C. 2007. The fate and management of pheasants (Phasianus colchicus) released in the UK. Imperial College

Warton DI, and Hui FKC. 2010. The arcsine is asinine: the analysis of proportions in ecology. Ecology 92:3-10. 10.1890/10-0340.1

Weckerly FW. 1998. Sexual-size dimorphism: influence of mass and mating systems in the most dimorphic mammals. Journal of Mammalogy 79:33-52.

Whiteside MA, Langley EJG, and Madden JR. 2016a. Males and females differentially adjust vigilance levels as group size increases: effect on optimal group size. Animal Behaviour 118:11-18.

Whiteside MA, Sage R, and Madden JR. 2015. Diet complexity in early life affects survival in released pheasants by altering foraging efficiency, food choice, handling skills and gut morphology. Journal of Animal Ecology 84:1480-1489.

Whiteside MA, Sage R, and Madden JR. 2016b. Multiple behavioural, morphological and cognitive developmental changes arise from a single alteration to early life spatial environment, resulting in fitness consequences for released pheasants. Royal Society Open Science 3.

Whiteside MA, van Horik JO, Langley EJG, Beardsworth CE, Capstick LA, and Madden JR. 2018. Patterns of association at feeder stations for Common Pheasants released into the wild: sexual segregation by space and time. Ibis 0. doi:10.1111/ibi.12632

Whiteside MA, van Horik JO, Langley EJG, Beardworth CE, Laker PR, and Madden JR. 2017. Differences in social preference between the sexes during ontogeny drive segregation in a precocial species. Behavioral Ecology and Sociobiology 71:103. 10.1007/s00265-017-2332-2

Wittzell H. 1991. Natural and sexual selection in the pheasant Phasianus colchicus. Lund University.

Young TP, and Isbell LA. 1991. Sex differences in giraffe feeding ecology: energetic and social constraints. Ethology 87:79-89.

Zuk M, and McKean KA. 1996. Sex differences in parasite infections: Patterns and processes. International Journal for Parasitology 26:1009-1024. https://doi.org/10.1016/S00207519(96)80001-4 
Figure 1

Distributions of the times for pheasants to appear after a time-matched control period, showing a clear break after $\sim 420$ mins.

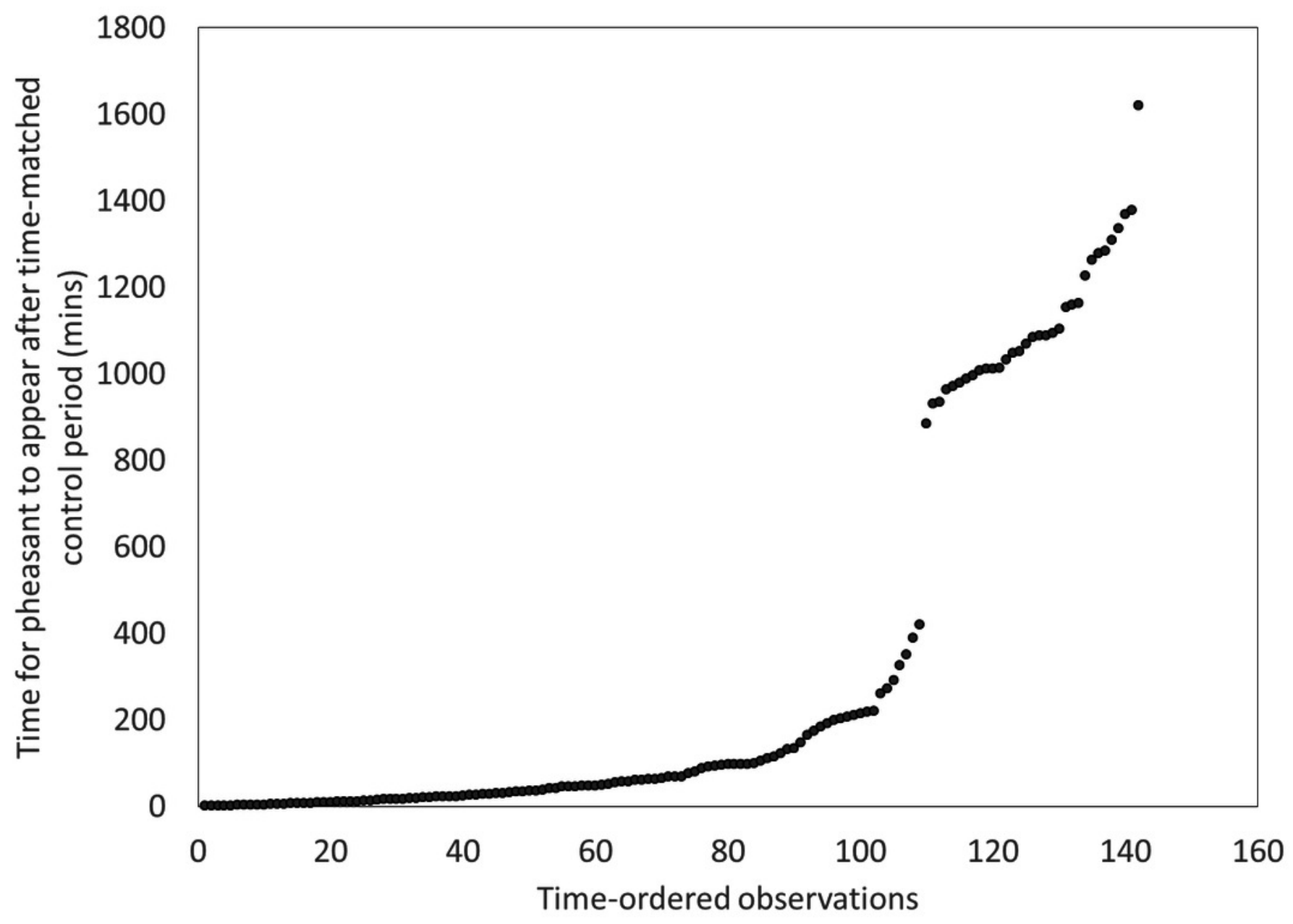


Figure 2

Time delay before a pheasant appears at a feeder after a fox has been present or a paired, time-matched control period $24 \mathrm{hrs}$ before the fox was sighted. Error bars = $\pm 1 S E$.

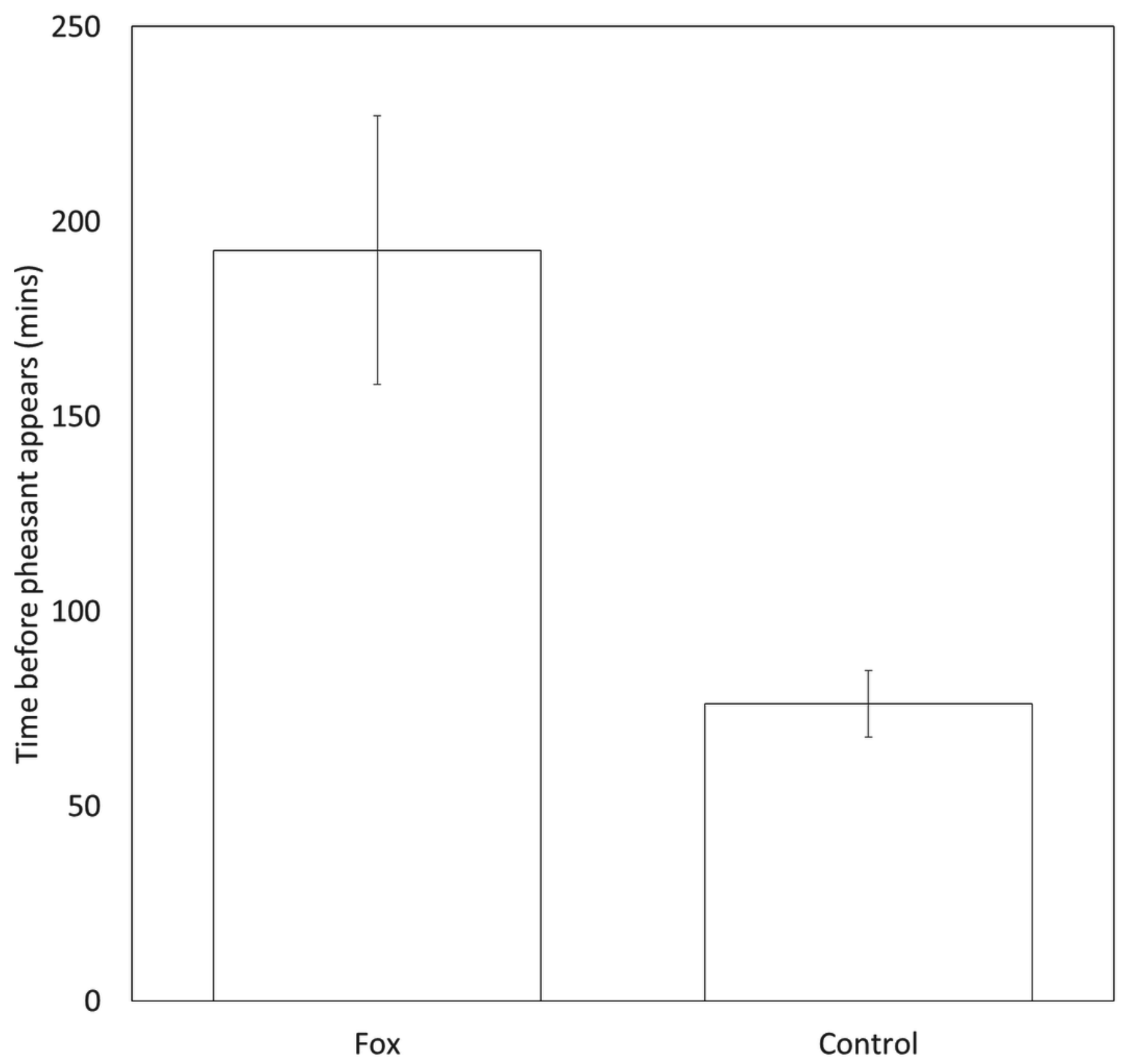


Figure 3

The mean mass of crop contents from birds shot in 2012. Error bars indicate +/- $1 \mathrm{SE}$

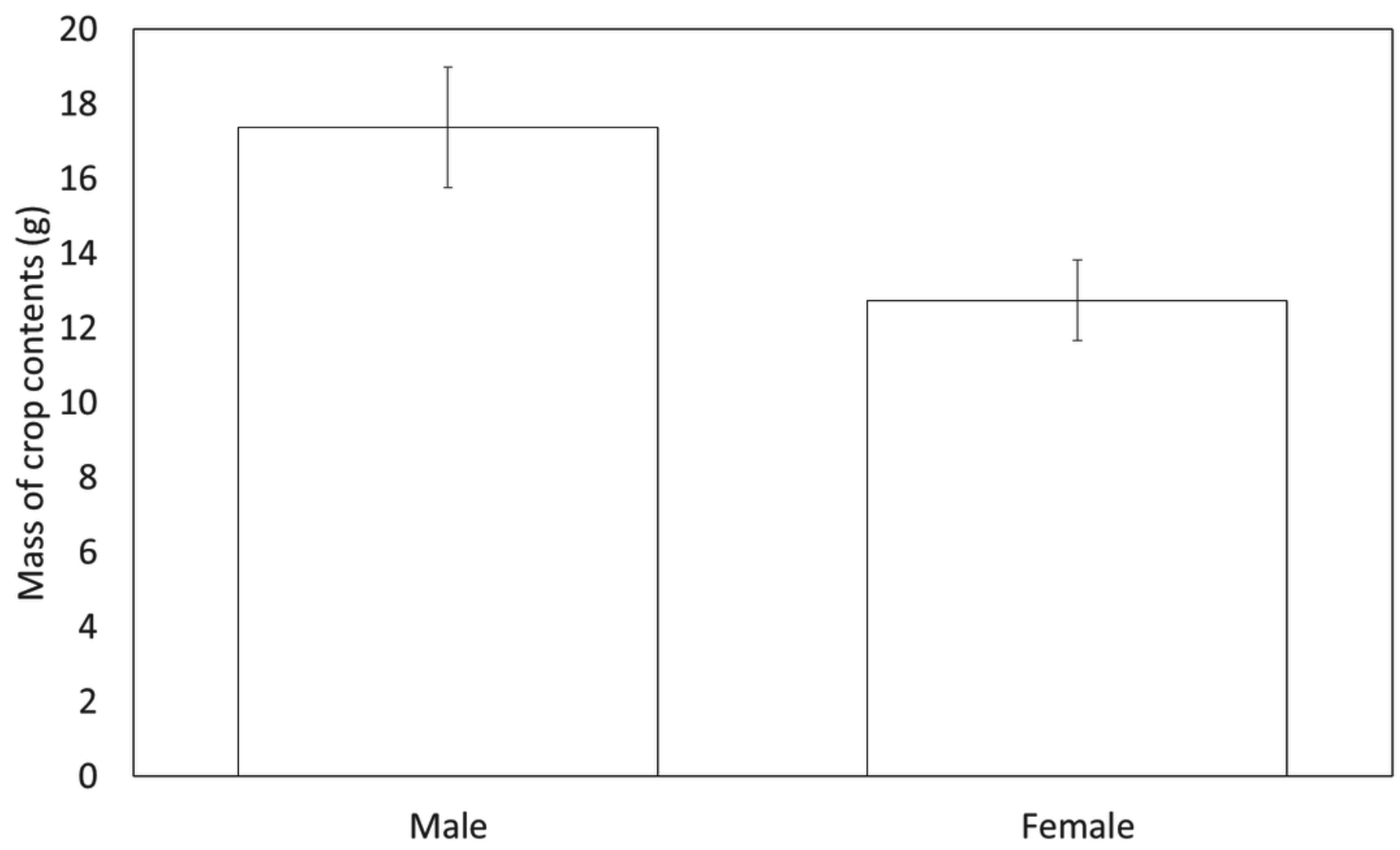




\section{Table $\mathbf{1}$ (on next page)}

A description, for each year, of the conditions each bird was reared under, the numbers per house, the release sex ratio along with what data was collected.

Representing a description, for each year, of the conditions each bird was reared under, the numbers per house, the release sex ratio along with what data was collected. The default environment was analogous to current industrial rearing conditions and acted as our control; a barren, spatially simple environment that offered a monotonous chick crumb diet that as ad lib and in excess. Within the parenthesis next to the measures denotes the sample size and which hypotheses it was used to test: FSH = Forage Selection Hypothesis; PRH = Predation Risk Hypothesis; $\mathrm{ABH}=$ Activity Budget Hypothesis. 


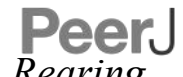

Rearing

(day 1 - release day)
Release day

(day 43-62)
Manuscript to be reviewed

(release day until 1 March)
Shooting season

(1 October - 1 February)
201210 replicates of 3 dietary treatments

1) $1 \%$ mealworms; 2) $5 \%$ mixed seed; 3) Control

Rearing numbers $=30$ per house

Release sex ratio(f:m) $=50: 50$

Large release number (game keeper)

$20133 \times 2$ design. 10 replicates of 3 dietary treatments

1) $1 \%$ mealworms; 2) $5 \%$ mixed seed; 3 ) Control

15 replicates of 2 structural treatments

1) access to perches; and 2) control (no perches)

Rearing numbers $=30$ per house

Release sex ratio(f:m) $=46: 54$

Large release number (game keeper)

2014 No environmental treatments.

All had control environment with the addition of

Supplementary mealworms and mixed seed and had access to perches

Rearing numbers $=50$ per house

Release sex ratio(f:m) $=46: 54$

Small release number (no game keeper)

2015 No environmental treatments.

All had control environment with the addition of

Supplementary mealworms and mixed seed and had access to perches

Rearing numbers $=50$ per house
Mass (871) Foraging behaviour (167: ABH)

Tarsus (871) Mortality (13: PRH)

Mass (901) Foraging behaviour (214: ABH)

Tarsus (901)

None

Mass (194)

Tarsus (194)
Resting behaviour (214: $\mathrm{ABH})$

Walking behaviour (214: ABH)

Mortality (18: PRH)

Feeder use relative to possible predation events (50: $\mathrm{PRH}$ )
Mass (233)

Tarsus (233)

Gut morphology (129: FSH)

Crop mass (159: FSH)

Mass (202)

Tarsus (202)

Crop samples (147: FSH)
None

Mortality (42: PRH)

None 
Release sex ratio(f:m) $=46: 54$

Small release number (no game keeper)

2 Table 1: Representing a description, for each year, of the conditions each bird was reared under, the numbers per house, the release 3 sex ratio along with what data was collected. The default environment was analogous to current industrial rearing conditions and acted 4 as our control; a barren, spatially simple environment that offered a monotonous chick crumb diet that as ad lib and in excess. Within 5 the parenthesis next to the measures denotes the sample size and which hypotheses it was used to test: FSH $=$ Forage Selection 6 Hypothesis; PRH = Predation Risk Hypothesis; ABH = Activity Budget Hypothesis. 


\section{Table 2 (on next page)}

The distribution, response variables, explanatory variables and random factors for all GLM and GLMMs used in the study 
Do sexes differ in mass

upon release into the

wild?

Do sexes differ in tarsus length upon release into the wild?

Normal

Normal

Do sexes differ in mass when shot as an adult?

Do sexes differ in tarsus length when shot as an adult?

Do sexes differ in their gut morphology when shot as adults

Do sexes differ in the mass of food found in their crop?

Do sexes differ in the time Normal spent foraging (2012)?
Mass

Sex of focal

House

Rearing treatment

(2012 and 2013

only)

Tarsus length

Sex of focal

House

Rearing treatment

(2012 and 2013

only)

Mass

Sex of focal

Age when shot

Rearing treatment

Tarsus length

Sex of focal

Age when shot

Rearing treatment

Length/ Mass/ Sex of focal

Volume

Age when shot

Rearing treatment

Mass

Sex of focal

Age when shot
Percentage of Sex of focal

time spent Time of day 


\begin{tabular}{|c|c|}
\hline foraging (logit & $(\mathrm{am} / \mathrm{pm})$ \\
\hline transformed) & Rearing treatment \\
\hline & Degree of aerial \\
\hline & protection \\
\hline & (Open/Closed \\
\hline & canopy) \\
\hline Likelihood & Sex of focal \\
\hline performing & Time of day \\
\hline behaviour & $(\mathrm{am} / \mathrm{pm})$ \\
\hline & Rearing treatment \\
\hline & Degree of aerial \\
\hline & protection \\
\hline & (Open/Closed \\
\hline & canopy) \\
\hline
\end{tabular}

Do sexes differ in

foraging, walking and

resting behaviours

(2013)?
Binomial
1

2 Table 2 The distribution, response variables, explanatory variables and random factors for all 3 GLM and GLMMs used in the study 


\section{Table 3(on next page)}

The mean mass in grams (range) of males and females released into the wild for three rearing seasons and the mass of adult birds shot in 2012 and 2013 


\begin{tabular}{llllll} 
Year (age) & Male mass $(g)$ & Female mass $(g)$ & $d f(d$-error) & $F$ & $P$ \\
\hline & & & & & \\
2012 (50 days) & $643.69(400-800)$ & $536.32(300-760)$ & $1(865)$ & 688.29 & $<0.001$ \\
2013 (43 days) & $489.42(350-630)$ & $412.07(220-540)$ & $1(889)$ & 169.90 & $<0.001$ \\
2015 (62 days) & $738.31(556-936)$ & $607.82(466-726)$ & $1(192)$ & 233.37 & $<0.001$ \\
& & & & & \\
2012 (Adult) & $1577.18(1140-$ & $1220.32(1010-$ & $1(124)$ & 830.03 & $<0.001$ \\
& $2200)$ & $1510)$ & & & \\
2013 (Adult) & $1574.63(1170-$ & $1223.66(920-1500)$ & $1(223)$ & 503.33 & $<0.001$
\end{tabular}

2 Table 3 The mean mass in grams (range) of males and females released into the wild for three 3 rearing seasons and the mass of adult birds shot in 2012 and 2013 


\section{Table 4 (on next page)}

The mean tarsus length in $\mathrm{mm}$ (range) of males and females released into the wild for three rearing seasons and the tarsus length of adult birds shot in 2012 and 2013 


\begin{tabular}{llllll} 
Year (age) & Male tarsus $(\mathrm{mm})$ & Female tarsus $(\mathrm{mm})$ & $d f(d$-error) & $F$ & $P$ \\
\hline 2012 (50 days) & $69.01(55-79.2)$ & $63.28(52.7-78)$ & $1(865)$ & $144.09<0.001$ \\
2013 (43 days) & $62.70(51.2-69.9)$ & $58.56(45.7-65)$ & $1(873)$ & $392.11<0.001$ \\
2015 (62 days) & $72.57(67.2-81.1)$ & $65.48(67.2-81.1)$ & $1(192)$ & $312.50<0.001$ \\
& & & & & \\
2012 (Adult) & $79.97(72.95-88.2)$ & $70.41(63.2-76.15)$ & $1(221)$ & $590.53<0.001$ \\
2013 (Adult) & $80.79(75.25-89.4)$ & $71.34(61.05-78.1)$ & $1(186)$ & $547.3<0.001$
\end{tabular}

1

2 Table 4 The mean tarsus length in mm (range) of males and females released into the wild for 3 three rearing seasons and the tarsus length of adult birds shot in 2012 and 2013 4 


\section{Table 5 (on next page)}

Mass $(\mathrm{g})$ and lengths $(\mathrm{mm})$ of male and female gut morphologies (degrees of freedom $=$ 1,128) for birds shot as adults in 2012 


\section{Relative}

\begin{tabular}{|c|c|c|c|c|c|c|}
\hline Dependent Variable & Sex & Mean & Std. Error & difference & $F$ & $P$ \\
\hline \multirow[t]{2}{*}{ Oesophagus Length } & Female & 111.75 & 1.82 & 1.10 & 23.720 & $<0.001$ \\
\hline & Male & 123.00 & 1.43 & & & \\
\hline \multirow[t]{2}{*}{ Oesophagus Mass } & Female & 1.79 & 0.08 & 1.27 & 23.227 & $<0.001$ \\
\hline & Male & 2.28 & 0.06 & & & \\
\hline \multirow[t]{2}{*}{ Crop Mass } & Female & 3.67 & 0.16 & 1.22 & 16.318 & $<0.001$ \\
\hline & Male & 4.48 & 0.12 & & & \\
\hline \multirow[t]{2}{*}{ Gizzard Mass } & Female & 22.55 & 0.53 & 1.18 & 33.098 & $<0.001$ \\
\hline & Male & 26.45 & 0.42 & & & \\
\hline \multirow[t]{2}{*}{ Intestine Length } & Female & 1146.23 & 15.78 & 1.09 & 25.942 & $<0.001$ \\
\hline & Male & 1248.35 & 12.37 & & & \\
\hline \multirow[t]{2}{*}{ Intestines Mass } & Female & 15.73 & 0.41 & 1.17 & 25.475 & $<0.001$ \\
\hline & Male & 18.34 & 0.32 & & & \\
\hline \multirow[t]{2}{*}{ Colon Length } & Female & 100.31 & 2.02 & 1.08 & 11.128 & $<0.001$ \\
\hline & Male & 108.88 & 1.58 & & & \\
\hline \multirow[t]{2}{*}{ Colon Mass } & Female & 2.08 & 0.09 & 1.27 & 24.731 & $<0.001$ \\
\hline & Male & 2.65 & 0.07 & & & \\
\hline \multirow[t]{2}{*}{ Average Ceca Length } & Female & 214.67 & 3.90 & 1.12 & 26.408 & $<0.001$ \\
\hline & Male & 240.13 & 3.06 & & & \\
\hline \multirow[t]{2}{*}{ Average Ceca Mass } & Female & 3.33 & 0.11 & 1.21 & 26.301 & $<0.001$ \\
\hline & Male & 4.04 & 0.09 & & & \\
\hline \multirow[t]{2}{*}{ Gizzard Volume } & Female & 45070.23 & 1501.27 & 1.13 & 9.514 & $<0.001$ \\
\hline & Male & 50955.55 & 1177.55 & & & \\
\hline
\end{tabular}

1

Table 5 Mass $(\mathrm{g})$ and lengths $(\mathrm{mm})$ of male and female gut morphologies (degrees of freedom $=$ 3 1,128) for birds shot as adults in 2012 


\section{Table 6(on next page)}

The percentage of males and females in the population with crop contents containing certain food for birds shot in 2013 with associated binomial statistics 


\begin{tabular}{llll} 
Food item & Males (\%) & Females (\%) & $P$ \\
\hline \multirow{2}{*}{ Wheat } & 62.39 & 74.51 & 0.19 \\
Maize & 58.12 & 56.86 & 0.54 \\
Grass & 68.38 & 62.75 & 0.42 \\
Oil Seed Rape & 8.55 & 7.84 & 0.58 \\
Insects & 10.26 & 13.73 & 0.33 \\
Seeds & 47.86 & 56.86 & 0.24 \\
Galls & 7.69 & 7.84 & 0.58 \\
Acorns & 23.93 & 11.76 & 0.08 \\
& & & \\
\hline
\end{tabular}

1

2 Table 6 The percentage of males and females in the population with crop contents containing

3 certain food for birds shot in 2013 with associated binomial statistics 


\section{Table 7 (on next page)}

The mean percentage of time spent foraging and the mean foraging bout length for males and females after release into the wild 


\begin{tabular}{lcccccccc} 
& \multicolumn{7}{c}{ Male } & \multicolumn{7}{c}{ Female } & & & \\
Behaviour & Year & Mean & SEM & Mean & SEM & $d f(d f$-error) & $F$ & $P$ \\
\hline \multirow{2}{*}{ Percentage Foraging } & 2012 & 32.41 & 2.24 & 35.23 & 3.2 & $1(139)$ & 0.01 & 0.98 \\
& 2013 & 33.1 & 2.1 & 29.53 & 2.19 & $1(186)$ & 1.84 & 0.18 \\
& & & & & & & & \\
Forage bout length & 2012 & 14.63 & 1.29 & 16.09 & 1.49 & $1(139)$ & 0.33 & 0.57 \\
& 2013 & 10.44 & 0.66 & 9.79 & 0.69 & $1(160)$ & 0.46 & 0.5
\end{tabular}

1

2 Table 7 The mean percentage of time spent foraging and the mean foraging bout length for 3 males and females after release into the wild 4 